\title{
COMPARTILHAMENTO DE RISCO NA AMÉRICA LATINA *
}

\author{
Breno Augusto da Silva e Silva ${ }^{\dagger}$ \\ NeLson da Silva ${ }^{\ddagger}$
}

\begin{abstract}
Resumo
Este trabalho buscou caracterizar o compartilhamento de risco na América Latina, utilizando renda e consumo per capita de 18 países latinoamericanos, 6 desenvolvidos (G6) e 11 emergentes, no período de 19512003. A metodologia utilizou dados em painel, cointegração e modelo de correção de erros. Observou-se que o compartilhamento de risco na América Latina, em geral, é baixo. Intra-América Latina, foi de $20 \%$ no curto prazo e $7 \%$ no longo prazo. Intra-América Latina e interpaíses desenvolvidos, $15 \%$ no curto prazo e de $4 \%$ no longo prazo. Intra-América Latina e interpaíses desenvolvidos mais os emergentes, $15 \%$ no curto prazo e $13 \%$ no longo prazo. Pelos resultados, uma maior integração financeira dos países da América Latina, intra e interpaíses, mais especificamente com os países emergentes, promoveria maior suavização do consumo na região.
\end{abstract}

Palavras-chave: Compartilhamento de Risco, Consumo, Produção, América Latina, Integração Financeira

\begin{abstract}
This work sought to characterize the risk sharing in Latin America, utilizing income and consumption per capita of 18 latin american, 6 developed and 11 emerging countries, over the period of 1951-2003. The methodology used data in panel, cointegration and error-correction model. Observed that the risk sharing in Latin America, in general, is low. Intra Latin America, it was $20 \%$ in short term and $7 \%$ in long term. Intra Latin America and inter developed countries, 15\% in short term and $4 \%$ in the long term. Intra Latin America and inter developed countries plus the emergent ones, $15 \%$ in short term and $13 \%$ in the long term. By results, a bigger financial integration of Latin America, intra and intercountries, more specifically with emerging countries, would promote bigger smoothing of its consumption.
\end{abstract}

Keywords: Risk Sharing, Consumption, Output, Latin America, Financial Integration

JEL classification: F36, F41,G15.

\footnotetext{
* Nós, autores, agradecemos os comentários dos pareceristas anônimos, isentado-os de possíveis erros ou omissões remanescentes, que são de nossa inteira responsabilidade.

${ }^{\dagger}$ Doutorando em Economia Aplicada pela Universidade Federal de Viçosa. E-mail: breno.silva@ufv.br

‡ Professor da Escola Superior de Administração e Gerência da Universidade do Estado de Santa Catarina. Avenida Madre Benvenuta, 2007 - Itacorubi, Florianópolis - SC / CEP 88035-001. Email: nelson.esag@udesc.br
} 


\section{Introdução}

Com o processo de globalização financeira, surgem oportunidades crescentes para que os países possam suavizar variações em seus consumos face a variações em suas rendas. Assim, eles podem melhorar seu nível econômico, aumentando também a estabilidade em suas economias. Segundo Obstfeld \& Rogoff (1996), negociações internacionais de ativos de risco podem alterar a forma como o consumo, o investimento e a conta corrente de um país respondem a choques não-antecipados na economia. Já para Kose et al. (2006), com a globalização financeira, ocorreriam ganhos no bem-estar, com a redução da volatilidade do consumo agregado e um descolamento do consumo em relação à renda nacional. Para Ventura (2008), desde que um país tivesse completo acesso ao compartilhamento de risco, todos os choques específicos do país seriam diversificáveis, ficando ele exposto apenas a choques agregados ou mundiais. Assim, variações no consumo de um país estariam mais ligadas a variações no consumo mundial do que a variações na produção do próprio país. Crucini \& Hess (2000), procurando enfatizar os compartilhamentos de risco, interpaíses e intrapaíses, reforçam que, com um completo acesso ao compartilhamento de risco, os choques idiossincráticos ou específicos de cada país seriam completamente diversificados, e variações no consumo de um país só seriam explicadas por mudanças no consumo mundial. Todas essas definições estão relacionadas ao compartilhamento de risco e retratam a importância da integração financeira para todas as economias.

Para que um país possa suavizar seu consumo, ele precisa evitar oscilações que possam fazer variar seu nível de bem-estar. Em geral, o Produto Interno Bruto (PIB) de cada país segue uma tendência histórica, mas não está imune a choques, sejam eles específicos em cada país, ou aqueles ocorridos na economia mundial. Esses choques podem afetar o nível do PIB de um país; por sua vez, o consumo, que, em geral está relacionado diretamente ao PIB, também é afetado. Dado que haja variações no consumo, haverá também alterações no bem-estar de um país.

Segundo Canova \& Ravn (1996), o completo compartilhamento de risco de consumo faria com que os agentes econômicos não alterassem seu consumo quando ocorressem choques em sua produção ou renda.

Assim, se em determinado ano, um país tivesse uma escassez de produção, devido a fenômenos naturais, por exemplo, ele poderia recorrer a um outro país que tivesse um excesso de produção, naquele mesmo ano. Isso é conhecido na literatura econômica com compartilhamento de risco.

A suavização do consumo pode também ser observada do ponto de vista individual, e, consequentemente, a agregação dos indivíduos leva à suavização do consumo de um país ou de uma economia. Para Canova \& Ravn (1996), o tema suavização do consumo por parte dos agentes econômicos, por meio de seguros contra flutuações na renda, é um assunto cada vez mais em voga nos modelos macroeconômicos dinâmicos.

O compartilhamento de risco é feito pela comercialização, não do produto físico, mas de papéis como títulos e ações, que podem representá-lo. Há também o mercado de crédito, no qual o país contrai empréstimos quando tem escassez de capital; ou fornece empréstimos quando possui um excesso de capital. De acordo com Allen \& Gale (1994), as trocas financeiras já ocorriam há milhares de anos em vários países. 
Segundo Obstfeld \& Rogoff (1996) e Lewis (1999), a literatura empírica documenta uma substancial falta de compartilhamento de risco internacional, e alguns testes econométricos para o compartilhamento de risco internacional mostram que o consumo é muito sensível aos choques, indicando que os mercados de ativos não são completos ou integrados, como pode ser observado em Obstfeld (1994), Canova \& Ravn (1996) e Lewis (1996), entre outros.

O compartilhamento de risco vem sendo estudado com maior ênfase mais recentemente, devido à maior abertura das economias de diversos países. Ele é um instrumento surgido dos processos de inovação financeira ao longo do tempo, e sua utilização é de fundamental importância para o desenvolvimento econômico; é promovido pela maior integração dos países e, consequentemente, dos seus mercados financeiros, permitindo uma maior suavização do consumo de cada país, com esse mesmo país tendo menor dependência com relação às variações na oferta de curto prazo.

A literatura econômica traz importantes trabalhos relacionados ao compartilhamento de risco.

Dentre esses trabalhos, os autores Canova \& Ravn (1996) fazem um estudo específico, utilizando dados em painel, para um grupo de países industrializados. Parte-se da idéia de que os agentes econômicos tendem a se proteger contra possíveis variações em sua renda, objetivando suavizar seu consumo, sendo esta idéia amplamente utilizada em vários modelos macroeconômicos atuais. O referencial teórico utilizado no trabalho é o compartilhamento de risco em um modelo mais simples inicialmente; sua ampliação é feita por meio de acréscimos ao modelo. A implementação metodológica despreza algumas restrições de seção cruzada impostas pela teoria. Os resultados obtidos na pesquisa mostraram que, para o consumo doméstico agregado, o risco é quase completamente compartilhado contra choques idiossincráticos reais, sejam eles monetários ou fiscais, no curto prazo. Já em períodos de tempo maiores, há uma maior variação.

De acordo com Sorensen \& Yosha (1998), há uma falta de compartilhamento de risco ex-ante, o que resulta em um baixo grau de compartilhamento de risco entre os países, no longo prazo.

Crucini \& Hess (2000) enfatizam, em seu trabalho, os compartilhamentos de risco, interpaíses e intrapaíses, reforçando que, com a existência de completo acesso ao compartilhamento de risco, os choques idiossincráticos ou específicos de cada país seriam completamente diversificados, e variações no consumo de um país só seriam explicadas por mudanças no consumo mundial. Os países em estudo foram aqueles da Organização para Cooperação de Desenvolvimento Econômico (OECD), mais especificamente, Canadá, Estados Unidos e Japão na análise intrapaíses. Os dados compreenderam os anos de 1975 a 1990. Os resultados mostraram que os compartilhamentos de risco intra-países e interpaíses são imperfeitos.

Para Kaminsky \& Schmukler (2003), a liberalização financeira e uma maior desregulamentação da economia poderiam levar a crises no curto prazo, mas, no longo prazo, levariam a uma maior estabilidade do sistema financeiro.

Segundo Schmukler (2004), apesar da ocorrência de um processo de aumento da globalização financeira nos últimos anos, o sistema financeiro internacional ainda está muito longe de tornar-se perfeitamente integrado. Ainda, segundo ele, os países desenvolvidos já participam desse processo de integração há mais tempo, enquanto os países considerados em desenvolvimento, como alguns dos países latino-americanos, que são o foco do presente traba- 
lho, apenas recentemente tomaram medidas mais profundas de liberalização de suas economias. De acordo com autor, o processo de globalização financeira fornece vários benefícios, o que levaria todos os países a se tornarem mais integrados. Especificamente para os países em desenvolvimento, o maior benefício seria o desenvolvimento de seus sistemas financeiros. A caracterização de sistemas financeiros desenvolvidos corresponderia a mercados financeiros mais completos, estáveis e com uma maior regulamentação entre si.

Ainda, para Schmukler (2004), a globalização financeira seria benéfica à medida que reduzisse as informações assimétricas e, consequentemente, os problemas da seleção adversa e do risco moral, sendo essas reduções consequências de um sistema financeiro mais estruturado. Um outro benefício seria decorrente do transbordamento de capitais que faria com que um país, com a possibilidade de receber um capital novo e anteriormente inexistente, pudesse suavizar mais o seu consumo. Em contrapartida, há também riscos que ocorreriam principalmente no curto prazo, período imediatamente após a abertura das economias: uma entrada de capitais em massa poderia prejudicar o sistema financeiro local. E uma forma de evitar alguns desses prejuízos seria a adoção de uma maior regulamentação. Entre os benefícios e os riscos da globalização financeira, o saldo de uma maior integração tenderia a ser positivo.

Kose et al. (2006) sugerem que as correlações entre taxa de crescimento do consumo e taxa de crescimento da produção não sofreram alterações significativas quando comparadas com o período de globalização da década de 1990 e o período anterior. Ainda, alguns resultados obtidos pelo autor mostram que as oportunidades relacionadas ao compartilhamento de risco estão diretamente ligadas ao grau de desenvolvimento financeiro de uma economia. Além disso, fatores como o grau de abertura de uma economia, choques nos termos de troca e nos gastos públicos seriam fatores importantes para determinar o grau de compartilhamento de risco dos países.

De acordo com Torre \& Schmukler (2007), no início da década de 1990, a maioria dos países da América Latina se engajou no processo de realização de algumas reformas denominadas pró-mercado. Tais reformas, que faziam parte do chamado Consenso de Washington, englobavam maior liberalização econômica, privatizações e uma desregulamentação da economia, ou seja, uma menor atuação do governo na atividade econômica, deixando a economia seguir o que era ditado pelo próprio mercado. Apesar de tais reformas, no caso latino-americano, elas parecem não ter sido tão profundas quanto aquelas ocorridas no mundo desenvolvido, o que pode ter levado a menores ganhos após o processo de globalização.

Para Leibrecht \& Scharler (2008), os resultados dos testes econométricos mostraram que, mesmo numa amostra de países considerados desenvolvidos como aqueles que compõem a Europa, o grau de compartilhamento é considerado baixo. Naquele trabalho, observou-se que apenas cerca de $30 \%$ dos choques idiossincráticos são compartilhados no curto prazo; já no longo prazo, esse percentual cai para $10 \%$. Observa-se que no curto prazo a possibilidade de os países se protegerem contra choques é maior, uma vez que grande parte de sua população tem acesso ao crédito. No longo prazo, essa possibilidade é reduzida, pois o compartilhamento de risco nesse prazo é realizado pelo mercado de títulos, mercado esse bem mais restrito à grande parte da população do que o mercado de crédito. Com relação ao tempo que um país leva para ajustar seu consumo a choques no produto, o mesmo trabalho mostrou que 
quanto maior o grau de integração de um país, maior é o seu tempo de ajuste a choques. Ou seja, economias mais integradas suavizam mais o seu consumo, fazendo com que ele seja mais estável, tendo um período de tempo maior para se alterar, face a mudanças no seu produto agregado.

Para Ventura (2008), que realizou um estudo para da região no período de 1972 a 2003, as economias latino-americanas seriam muito mais afetadas por choques idiossincráticos em suas rendas, que seriam transmitidos para o consumo e por sua vez para o bem-estar dos países. As conclusões do autor são que os riscos idiossincráticos seriam relativamente mais importantes do que os riscos agregados para explicar as oscilações no consumo; e que alguns países da região já usufruiriam de algum compartilhamento de risco (ainda que em pequena extensão). Uma observação mais importante é que os países latino-americanos compartilhariam uma fração maior de seus riscos com os próprios países da região do que com outros países, como os da Organização para Cooperação de Desenvolvimento Econômico (OCDE).

Deve-se ressaltar o estudo do tema compartilhamento de risco ou diversificação internacional de risco para a região latino-americana, pois os trabalhos sobre o compartilhamento de risco no mundo são recentes, havendo para a América Latina poucos trabalhos de grande relevância sobre esse assunto.

A existência de mercados de capitais bem desenvolvidos propiciaria aos países compartilhar risco pela negociação de ativos, de acordo com o seu produto em determinado ano. Se o país tivesse uma produção acima da média histórica, ele venderia ativos no mercado para outros países; já na hipótese de um produto abaixo da média histórica, o país aumentaria o seu passivo, recorrendo a ativos externos.

Deve-se observar que as mudanças nas carteiras seriam ajustes anteriores aos choques na economia, ou seja, uma medida ex-ante. E recorrer ao mercado de crédito para emprestar ou pegar empréstimos seria uma medida ex-post, já que aconteceria após a ocorrência do choque.

Pelos resultados desses trabalhos, pode-se inferir que economias mais desenvolvidas e, portanto, com um mercado de capitais mais desenvolvido, tenderiam a suavizar mais seu consumo, propiciando uma maior estabilidade à sua própria economia e ao bem-estar das pessoas. Outro importante aspecto a ser destacado é que o compartilhamento de risco tende a ser maior no curto prazo. Esse fator poderia estar relacionado às incertezas, que são maiores, quanto maior for o período de tempo, e à inexistência de um mercado de capitais desenvolvido em muitos países. Vale ressaltar que o compartilhamento de risco no longo prazo ocorre por meio dos mercados de capitais.

Os resultados obtidos por outros autores são semelhantes aos do presente trabalho, ou seja, há uma falta de compartilhamento de risco. Diferenças ocorreram com relação aos países estudados, pois trabalhos anteriores focaram no mercado internacional como um todo, ou nos países desenvolvidos, mais especificamente aqueles que compõem o bloco europeu ou os Estados Unidos, onde o grau de integração já é de alguma forma, considerável.

Já a especificidade desse trabalho está em estudar particularmente a América Latina, historicamente com uma economia menos robusta, propiciando, assim, uma comparação dos resultados obtidos para essa região com aqueles de outras regiões.

Este trabalho caracteriza o compartilhamento de risco na América Latina, pela utilização de dados sobre consumo e produto de 18 países latinoamericanos, além de 6 países desenvolvidos e 11 países emergentes. A me- 
todologia utiliza dados em painel, como em outros importantes trabalhos da literatura econômica, dentre eles o trabalho de Leibrecht \& Scharler (2008).

As contribuições do presente trabalho são cinco. A primeira é verificar se o grau de compartilhamento de risco entre os países da América Latina é baixo, com sua renda e seu consumo seguindo uma trajetória comum ao longo ao tempo, ou seja, fazendo com que o consumo do país seja dependente da sua renda, sendo a consequência dessa falta de compartilhamento de risco uma maior instabilidade econômica. A segunda contribuição é verificar se o tempo de ajustamento do consumo dos países da América Latina, quando da ocorrência de choques da economia, é pequeno, ou seja, o seu consumo se mantém imune a choques apenas por um curto período de tempo. A terceira contribuição do trabalho é verificar se os países da América Latina são ainda pouco integrados, perdendo assim possibilidades de manter seu nível de consumo mais estável ao longo do tempo e um maior nível de bem- estar. A quarta contribuição é verificar se, no curto prazo, o compartilhamento de risco na América Latina é maior intrapaíses, e no longo prazo maior interpaíses, considerando os países emergentes. A quinta contribuição é verificar o comportamento do grau compartilhamento de risco na América Latina ao longo do tempo, de acordo com os vários acontecimentos econômicos, dentre eles o processo de globalização financeira intensificado no início dos anos de 1990.

O período estudado nesse trabalho compreendeu os anos entre 1951 e 2003, com dados anuais. Para verificar o nível de compartilhamento de consumo entre os países da América Latina, foram estimados três parâmetros, $\beta$, $\gamma$, e $\lambda$, correspondentes a, respectivamente: parcela do consumo sensível a choques, no longo prazo; fração dos choques não suavizada, no curto prazo; e tempo de ajustamento do consumo quando da ocorrência de choques.

Os resultados levaram à conclusão que, em geral, há um baixo grau de compartilhamento de risco da América Latina. Mas esse compartilhamento é maior entre a América Latina e alguns países emergentes, do que apenas intra América Latina, pelo menos considerando-se o compartilhamento no longo prazo.

É importante ressaltar o estudo desse tema para a América Latina, pois há poucos trabalhos de grande relevância sobre compartilhamento de risco para a região.

Na seção 2, é apresentado o modelo teórico, em que se utiliza o modelo de Arrow-Debreu, segundo o qual existe um mercado para se proteger contra cada tipo de risco. Na seção 3, são descritas as equações do modelo analítico, em que são obtidos os parâmetros estimados. A seção 4 traz os resultados e suas respectivas interpretações. Por fim, a seção 5 traz a conclusão do presente trabalho.

\section{Modelo Teórico ${ }^{1}$}

Negócios internacionais em ativos de risco podem alterar a forma de consumo, investimento e da conta corrente, para choques não antecipados. Assim, o aumento no produto doméstico em determinado ano, acima da média histórica,

\footnotetext{
${ }^{1}$ Para maiores detalhes do Modelo Teórico, observar as equações em Anexo. Àquela seção tem por objetivo manter o artigo auto-contido, e toma parte do desenvolvimento de Obstfeld \& Rogoff (1996, capítulo 5).
} 
é balanceado por uma menor entrada de ativos estrangeiros para esse país, ou por uma saída de ativos correspondentes ao excesso de oferta (Obstfeld \& Rogoff 1996).

Assim, segundo Obstfeld \& Rogoff (1996), renda, consumo e conta corrente permaneceriam estáveis.

Alguns fatores, como risco moral e existência de contratos imperfeitos, fazem com que os países não possam se proteger completamente contra os riscos por eles enfrentados.

Assume-se, segundo Arrow (1964) e Debreu (1959), que há um mercado para se proteger contra qualquer tipo de risco. Apesar de ser uma assunção um pouco extrema, ela é um importante ponto de partida com relação aos efeitos do risco e de mercados relacionados ao risco na economia.

O Modelo Arrow-Debreu sobre mercados completos permite pensar a alocação de risco da mesma forma que se calcula a alocação de commodities ao longo do tempo.

Uma vantagem relacionada à análise dos mercados completos está relacionada à sua forte base empírica, incluindo diversificação de carteira internacional, apreçamento de ativos e caminhos de crescimento do consumo mundial. Em alguns casos, essa base teórica sobre mercados completos não é corroborada por testes empíricos, demonstrando exatamente alguma das imperfeições de mercado que ocorrem na realidade (Obstfeld \& Rogoff 1996).

Para Arrow (1996), apenas sob certas condições o compartilhamento de risco e os seguros se tornariam transações vantajosas. Ele tenta diferenciar um modelo considerado ideal de um modelo considerado real. Sua crítica é exposta, ao citar, por exemplo, o fato de que em um mercado competitivo ideal em que haja compartilhamento de risco, os pagamentos recebidos pelos indivíduos dependem de todas as incertezas em determinado tempo, não considerando apenas quem está segurado. Ainda nesse sistema, os prêmios pagos dependem dos danos totais, enquanto na realidade deveriam levar em a conta a distribuição entre os indivíduos. Essa seria, portanto, uma das limitações de um modelo quando são considerados mercados completos.

\section{Modelo Analítico}

\subsection{Estimativa dos Parâmetros de Compartilhamento de Risco}

Se os agentes econômicos podem negociar ativos nos mercados financeiros internacionais, que são completos no sentido de Arrow-Debreu, a utilidade marginal do consumo se iguala entre os países (Leibrecht \& Scharler 2008).

Assumindo preferências de aversão ao risco relativamente constantes, a alocação ótima de consumo deve satisfazer a seguinte equação:

$$
\log c_{i t}=\alpha_{i}+\log c_{j t}
$$

em que $c_{i t}$ e $c_{j t}$ são o consumo real per capita nos tempos $t=1, \ldots, T$, nos países $i=1, \ldots, N$ e $j=1, \ldots, N$ e $\alpha$ i se refere ao efeito específico de um dado país.

Substituindo o país fixado $j$, pelo resto do mundo, chega-se a:

$$
\log c_{i t}=\alpha_{i}+\log c_{t}
$$


em que $c_{t}$ corresponde ao consumo per capita médio de um determinado grupo de países ou de uma região, caracterizada no trabalho como o resto do mundo.

Da equação (1), verifica-se que a taxa de crescimento do consumo é altamente correlacionada entre países, não dependendo de choques idiossincráticos; ou melhor, esses choques são completamente diversificados pelo resto do mundo. Observa-se que apenas o $t$, referente ao tempo varia; já o j, referente aos países, passa a ser constante.

Empiricamente, entretanto, os mercados financeiros demonstram ser incompletos. Assim, os países não poderiam se proteger completamente contra os choques na economia, que influenciariam o produto dos países, aqui colocado como yit.

Além disso, a sensibilidade do consumo em relação às variações na renda seria tanto maior, quanto maior fosse a restrição no mercado de crédito. Isso estaria relacionado ao curto, já que no longo prazo a suavização do consumo ocorreria pela mudança nas carteiras de ativos dos países. Se a população de determinado país não tem acesso a crédito, seu consumo terá que seguir a sua renda.

Para analisar a dependência do consumo em relação aos choques idiossincráticos tem-se: $\tilde{y}_{i} t=\log y_{i t}-\log _{y t}$ que mede a variação na renda.

Já a seguinte equação mede a variação no consumo quando há um choque idiossincrático na renda:

$$
\tilde{c}_{i t}=\alpha_{i}+\beta \tilde{y}_{i t}
$$

em que $\tilde{c}_{i t}=\log c_{1 t}-\log c_{t}$

$\mathrm{Na}$ equação (3), as variáveis são cointegradas. Sendo de fato cointegradas, pode-se estimar um mecanismo de correção de erro pela seguinte equação:

$$
\tilde{c}_{i t}=\gamma \Delta c \tilde{y}_{i t}-\lambda\left(\tilde{c}_{i t-1}-\alpha_{i}-\beta \tilde{y}_{i t-1}\right)+e_{i t}
$$

Assim, há três parâmetros a serem estimados: $\beta, \gamma$, e $\lambda$.

Segundo Asdrubali et al. (1996), $\gamma$ significa a medida de exposição a choques. Pode-se dizer que representa a fração dos choques não suavizada, nem mesmo pelos mercados financeiros. Assim, se $\gamma=0$, diz-se que há um perfeito compartilhamento de risco; já quando $\gamma=1$, o consumo é totalmente dependente da renda. Quando $0<\gamma<1$, há um grau de compartilhamento de risco não perfeito. Ele é imperfeito devido a restrições no crédito ou à falta de acesso a mercados de capitais, onde poderia ocorrer a comercialização de ativos e a mudança nas carteiras dos países. Para $\gamma>1$, o grau de volatilidade do país seria tão grande que poderia ser considerado pior do que uma autarquia (economia totalmente fechada ao mercado externo). Nesse último caso, o exercício de uma política fiscal pelo governo do país ou a entrada de um fluxo de capitais faria com que houvesse uma piora na suavização do consumo, pois todo o aumento da renda seria gasto no consumo daquele período, viesando-o em relação à média histórica.

O parâmetro $\beta$ mostraria em que extensão o consumo é sensível aos choques idiossincráticos, no longo prazo. O parâmetro $\lambda$ seria a velocidade de ajustamento do consumo, como resposta a choques no produto. Quanto maior o valor de $\lambda$, maior o tempo de ajustamento. Isso significa que o país tem um maior grau de integração com os outros mercados financeiros e maior é o seu compartilhamento de risco. 


\subsection{Procedimentos Econométricos}

Para as implementações econométricas, o presente trabalho utilizou Dados em Painel, também chamados de dados combinados. O processo de estimação dos parâmetros foi composto pelos Testes de Raízes Unitárias para Dados em Painel, Teste de Cointegração de Pedroni, Efeitos Fixos e Aleatórios, Teste de Hausman, dentre outros.

O software utilizado para as estimações foi o Econometic Views - E-Views, versão 6. Os dados de consumo e de produto per capita dos países foram utilizados na estimação em painel, pelo método de Mínimos Quadrados Generalizados (MQG). Foram utilizados efeitos fixos e efeitos aleatórios e, por meio do teste de Hausman, verificou-se qual deles era mais adequado.

\section{Dados e Resultados}

\subsection{Dados}

Os dados utilizados nesse trabalho correspondem a séries históricas do produto real per capita e do consumo real per capita, de 35 países, divididos América Latina, Bloco do G-6 e alguns emergentes. Da América Latina temos 18 países: Argentina, Bolívia, Brasil, Chile, Colômbia, Costa Rica, El Salvador, Equador, Guatemala, Honduras, México, Nicarágua, Panamá, Paraguai, Peru, República Dominicana, Uruguai e Venezuela. O bloco G-6 foi constituído pelos sete países mais ricos do mundo, excluindo-se a Alemanha, devido à falta de dados para esse país. Os seis países utilizados são: Canadá, Estados Unidos, França Itália, Japão e Reino Unido. Os 11 países dentre os emergentes são: África do Sul, China, Egito, Filipinas, Índia, Israel, Malásia, Marrocos, Paquistão, Tailândia e Turquia. Os valores agregados das variáveis são calculados como médias ponderadas:

$$
y_{t}=\sum_{i=1 \neq j}^{18} w_{i t} y_{i t} \text { e } c_{t}=\sum_{i=1 \neq j}^{18} w_{i t} c_{i t}
$$

O peso $w_{i t}$ é calculado da seguinte maneira:

$$
w_{i t}=\frac{\text { pop }_{i t}}{\sum_{\substack{i=1 \\ i \neq j}}^{18} p o p_{j t}}
$$

em que pop $_{i t}$ e $p o p_{j t}$ são as populações dos países $i$ e $j$, respectivamente, no tempo $t$.

Assim, quando se calcula a variação do consumo real per capita e do produto real per capita de um país em relação à variação do resto do mundo, esse país não é incluído no agregado. Por isso, tem-se $i \neq j$.

O cálculo da variação da produção e do consumo per capita em relação à média mundial foi feito apenas para os países da América Latina, sendo que os países do G6 e os emergentes foram incluídos no cálculo da média mundial. Não foram calculadas variações na produção e no consumo em relação à média mundial para o G6 e os emergentes.

O período estudado é de 1951 a 2003, dados anuais. A fonte de dados é a Penn World Table, de Heston et al. (2006). 


\subsection{Resultados}

Resultados dos Testes de Raízes Unitárias e de Cointegração

O teste de Raízes Unitárias foi realizado em nível e em primeira diferença para determinar o grau de integração das séries. Utilizou-se apenas intercepto, pois se trabalhou com variações das séries. A estatística foi do teste foi a ImPesaran-Shin.

A Tabela1 mostra os valores do teste de raízes unitárias.

Ao realizar o teste de raízes unitárias para as séries variação do consumo per capita e variação da renda per capita, em nível, com intercepto e sem tendência, a hipótese nula de existência de uma raiz unitária não é rejeitada ao nível de $5 \%$ de significância estatística.

A não-estacionariedade das séries poderia causar problemas na estimação, caso elas não fossem cointegradas. Por esse motivo, foi feito o teste de Pedroni, um teste usualmente relacionado à cointegração, para dados painel. A existência de cointegração se baseia nos resultados das estatísticas rho, PP e ADF (Tabela2).

O teste de cointegração de Pedroni tem como hipótese alternativa a existência de coeficientes Auto-Regressivos (AR) comuns. As três estatísticas utilizadas no teste são significativas ao nível de $5 \%$ de significância estatística, rejeitando-se a hipótese nula e aceitando-se a hipótese alternativa de existência de cointegração.

\section{Resultados dos Estimadores de Compartilhamento de Risco e Testes Adicionais - Parâmetros da Equação Geral}

A busca de resultados relacionados ao compartilhamento de risco de consumo entre os países da América Latina se baseou na estimação de três parâmetros principais, $\beta, \gamma$, e $\lambda$, presentes nas seguintes equações (3) e (4), descritas anteriormente:

$$
\tilde{c}_{i t}=\alpha_{i}+\beta \tilde{y}_{i t}
$$

$$
\Delta \tilde{c}_{i t}=\gamma \Delta \tilde{y}_{i t}-\lambda\left(\tilde{c}_{i t-1}-\alpha_{i}-\beta \tilde{y}_{i t-1}\right)+e_{i t}
$$

$\mathrm{O} \gamma$ seria a medida de exposição a choques. É ainda um parâmetro de curto prazo, período em que a suavização do consumo é feita pelo acesso ao mercado de crédito. Pode-se dizer que representa a fração dos choques que não é suavizada, nem mesmo pelos mercados financeiros. Sendo assim, quanto menor o valor de $\gamma$, maior o grau de compartilhamento de risco.

O parâmetro $\beta$ mostraria em que extensão o consumo é sensível aos choques idiossincráticos, no longo prazo. Essa sensibilidade a choques, no longo prazo, dependeria de quanto o país comercializa ativos em termos mundiais, ou ainda, quão extensa é sua carteira. Quanto menor o $\beta$, menor a sensibilidade do país a choques e, portanto, maior seu grau de compartilhamento de risco.

O outro parâmetro $\lambda$ seria o tempo de ajustamento do consumo, como resposta a choques no produto. Quando maior o valor de $\lambda$, mais o país poderia suavizar seu consumo, sem fazer mudanças bruscas em um curto período de tempo, retratando um maior grau de integração financeira e maior compartilhamento de risco. 
Tabela 1: Resultado dos Testes de Raízes Unitárias

\begin{tabular}{|c|c|c|c|c|}
\hline \multicolumn{5}{|c|}{ América Latina } \\
\hline Variáveis & $\begin{array}{l}\text { Estatística Im, } \\
\text { Pesaran e Shin }\end{array}$ & P-Valor $^{*}$ & $\begin{array}{c}\text { Seções } \\
\text { Cruzadas }\end{array}$ & Observações \\
\hline \multicolumn{5}{|c|}{ Hipótese Nula: A série é I(1) (tem uma raiz unitária) } \\
\hline$\tilde{c}_{i t}$ & 0,78 & 0,78 & 18 & 915 \\
\hline$\tilde{y}_{i t}$ & 1,54 & 0,93 & 18 & 928 \\
\hline \multicolumn{5}{|c|}{ Hipótese Nula: A série é I(2) (tem duas raízes unitárias) } \\
\hline$\tilde{c}_{i t}$ & $-15,43$ & 0,00 & 18 & 882 \\
\hline$\tilde{y}_{i t}$ & $-12,91$ & 0,00 & 18 & 874 \\
\hline \multicolumn{5}{|c|}{ América Latina + G6 } \\
\hline Variáveis & $\begin{array}{l}\text { Estatística Im, } \\
\text { Pesaran e Shin }\end{array}$ & P-Valor ${ }^{*}$ & $\begin{array}{c}\text { Seções } \\
\text { Cruzadas }\end{array}$ & Observações \\
\hline \multicolumn{5}{|c|}{ Hipótese Nula: A série é I(1) (uma raiz unitária) } \\
\hline$\tilde{c i t}$ & 1,73 & 0,95 & 18 & 905 \\
\hline$\tilde{y}_{i t}$ & 2,64 & 0,99 & 18 & 920 \\
\hline \multicolumn{5}{|c|}{ Hipótese Nula: A série é I(2) (tem duas raízes unitárias) } \\
\hline$\tilde{c}_{i t}$ & $-12,02$ & 0,00 & 18 & 878 \\
\hline$\tilde{y}_{i t}$ & $-14,43$ & 0,00 & 18 & 899 \\
\hline \multicolumn{5}{|c|}{ América Latina + G6 + Emergentes } \\
\hline Variáveis & $\begin{array}{l}\text { Estatística Im, } \\
\text { Pesaran e Shin }\end{array}$ & P-Valor ${ }^{*}$ & $\begin{array}{c}\text { Seções } \\
\text { Cruzadas }\end{array}$ & $\overline{\text { Observações }}$ \\
\hline \multicolumn{5}{|c|}{ Hipótese Nula: A série é I(1) (uma raiz unitária) } \\
\hline$\tilde{c}_{i t}$ & 2,70 & 0,99 & 18 & 910 \\
\hline$\tilde{y}_{i t}$ & 4,98 & 1,00 & 18 & 917 \\
\hline \multicolumn{5}{|c|}{ Hipótese Nula: A série é I(2) (tem duas raízes unitárias) } \\
\hline$\tilde{c}_{i t}$ & $-14,51$ & 0,0000 & 18 & 875 \\
\hline$\tilde{y}_{i t}$ & $-9,79$ & 0,0000 & 18 & 874 \\
\hline
\end{tabular}

${ }^{*}$ Valor observado da estatística Im-Peasaran-Shin significativa, ao nível de 5\% de significância.

Fonte: Resultados da pesquisa. 
Tabela 2: Resultado do Teste de Cointegração de Pedroni

\begin{tabular}{|c|c|c|c|c|}
\hline \multicolumn{5}{|c|}{ América Latina } \\
\hline Método & Coeficientes & P-Valor ${ }^{*}$ & $\begin{array}{l}\text { Coeficientes } \\
\text { Ponderados }\end{array}$ & P-Valor \\
\hline \multicolumn{5}{|c|}{ Hipótese Alternativa: Coeficientes AR comuns } \\
\hline Estatística rho & $-3,10$ & 0,00 & $-4,85$ & 0,00 \\
\hline Estatística PP & $-2,82$ & 0,00 & $-4,21$ & 0,00 \\
\hline Estatística ADF & $-3,21$ & 0,00 & $-4,93$ & 0,00 \\
\hline \multicolumn{5}{|c|}{ América Latina + G6 } \\
\hline Método & Coeficientes & P-Valor ${ }^{*}$ & $\begin{array}{l}\text { Coeficientes } \\
\text { Ponderados }\end{array}$ & P-Valor \\
\hline \multicolumn{5}{|c|}{ Hipótese Alternativa: Coeficientes AR comuns } \\
\hline Estatística rho & $-2,02$ & 0,05 & $-3,29$ & 0,00 \\
\hline Estatística PP & $-2,08$ & 0,04 & $-3,34$ & 0,00 \\
\hline Estatística ADF & $-2,36$ & 0,02 & $-3,45$ & 0,00 \\
\hline \multicolumn{5}{|c|}{ América Latina + G6 + Emergentes } \\
\hline Método & Coeficientes & P-Valor ${ }^{*}$ & $\begin{array}{l}\text { Coeficientes } \\
\text { Ponderados }\end{array}$ & P-Valor \\
\hline \multicolumn{5}{|c|}{ Hipótese Alternativa: Coeficientes AR comuns } \\
\hline Estatística rho & 3,55 & 0,00 & 3,07 & 0,00 \\
\hline Estatística PP & 5,04 & 0,00 & 4,14 & 0,00 \\
\hline Estatística ADF & 4,87 & 0,00 & 4,15 & 0,00 \\
\hline
\end{tabular}

Buscou-se verificar as variações no consumo per capita dos países da América Latina em função de sua produção (renda) per capita e em função de variações no consumo per capita mundial. Fizeram-se três análises: uma chamada intrapaíses, em que o consumo per capita mundial ficou restrito à média ponderada apenas do bloco latino americano. Nas outras duas análises, chamadas interpaíses, incluíram-se primeiramente países do G6 e depois, além desses, alguns países emergentes no agregado mundial.

$\mathrm{Na}$ análise intrapaíses, ou seja, considerando apenas a América Latina, ao estimar a equação (3) do modelo empírico, levando-se em conta efeitos aleatórios, obteve-se um parâmetro $\beta=0,93$ para a América Latina, analisando-se apenas o compartilhamento de risco intrapaíses. Consideraram-se todos os coeficientes constantes ao longo do tempo, com mudanças apenas entre países. A interpretação desse parâmetro é que aproximadamente $93 \%$ do consumo da América Latina é sensível aos choques idiossincráticos no longo prazo. É o mesmo que dizer que apenas $7 \%$ do consumo dessa região é suavizado no longo prazo. Logo, por esse parâmetro, compartilhamento de risco de longo prazo da América Latina, intrapaíses, é baixo. Ao estimar o parâmetro $\gamma$, de curto prazo, partindo da equação (4) do modelo empírico, levando-se em conta efeitos aleatórios, o valor encontrado foi $\gamma=0,80$. A interpretação desse 
parâmetro é que aproximadamente $80 \%$ dos choques idiossincráticos sofridos pelos países da América Latina não são suavizados no curto prazo. É o mesmo que dizer que $20 \%$ desses choques são suavizados no curto prazo pelo mercado de crédito. O parâmetro $\lambda$, também estimado pela equação (4) do modelo empírico, também com efeitos aleatórios, foi $\lambda=-0,11$. A interpretação do parâmetro é que o tempo para ajustamento do consumo dos países da América Latina é de aproximadamente -0,11. Para esse parâmetro, não há uma unidade de medida específica, mas entende-se apenas que quanto maior seu valor (em módulo), maior é o tempo que um país tem para ajustar o consumo em decorrência de choques em sua produção.

$\mathrm{Na}$ análise interpaíses, considerando-se o consumo da América Latina mais o consumo dos países do G6, como sendo o agregado mundial, ao estimar a equação (3) do modelo empírico, levando-se em conta efeitos aleatórios, obteve-se um parâmetro $\beta=0,96$. A interpretação desses parâmetros é que aproximadamente $96 \%$ do consumo da América Latina é sensível aos choques idiossincráticos no longo prazo, levando-se em conta o G6. É o mesmo que dizer que apenas $4 \%$ do consumo dessa região é suavizado no longo prazo. Logo, por esse parâmetro, o compartilhamento de risco de longo prazo da América Latina, interpaíses, considerando-se o G6, é ainda menor que o compartilhamento de risco intra América Latina. Também para América Latina mais G6, ao estimar o parâmetro $\gamma$, de curto prazo, partindo da equação (4) do modelo empírico, levando-se em conta efeitos aleatórios, o valor encontrado foi $\gamma=0,85$. A interpretação desse parâmetro é que aproximadamente $85 \%$ dos choques idiossincráticos sofridos pelos países da América Latina não são suavizados no curto prazo. É o mesmo que dizer que $15 \%$ desses choques são suavizados no curto prazo, pelo mercado de crédito. O grau de compartilhamento de risco de curto prazo com a inclusão do G6 também é menor do que o valor intra América Latina. O parâmetro $\lambda$, também estimado pela equação (4) do modelo empírico, e também com efeitos aleatórios, foi $\lambda=-0,11$. A interpretação do parâmetro é que o tempo para ajustamento do consumo dos países da América Latina é de aproximadamente -0,11. Para esse parâmetro, não há mudanças significativas em relação ao valor intra América Latina. Tal redução no compartilhamento de risco, quando incluídos países do G6, segundo Crucini e Hess (2000), estaria relacionada ao fato de o compartilhamento de risco intra-países (dentro de uma mesma região) tender a ser maior do que o compartilhamento de risco interpaíses (quando se incluem outros países externos a uma região específica na análise). Tal resultado ocorreria por fatores como características econômicas comuns entre países próximos, menor assimetria de informações, menores custos de transação, o que promoveria um maior compartilhamento de risco intrapaíses.

$\mathrm{Na}$ análise interpaíses, considerando o consumo da América Latina mais o consumo dos países do G6 e emergentes como sendo o agregado mundial, ao estimar a equação (3) do modelo empírico, levando-se em conta efeitos aleatórios, obteve-se um parâmetro $\beta=0,87$. A interpretação desses parâmetros é que aproximadamente $87 \%$ do consumo da América Latina é sensível aos choques idiossincráticos no longo prazo, levando-se em conta G6 e emergentes. É o mesmo que dizer que apenas $13 \%$ do consumo dessa região é suavizado no longo prazo. Logo, por esse parâmetro, o compartilhamento de risco de longo prazo da América Latina, interpaíses, considerando-se o G6 e emergentes, é maior que o compartilhamento de risco intra América Latina. Também para América Latina mais G6 e emergentes, ao estimar o parâmetro 
$\gamma$, de curto prazo, partindo da equação (4) do modelo empírico, levando-se em conta efeitos aleatórios, o valor encontrado foi $\gamma=0,85$. A interpretação desse parâmetro é que aproximadamente $85 \%$ dos choques idiossincráticos sofridos pelos países da América Latina não são suavizados no curto prazo. É o mesmo que dizer que $15 \%$ desses choques são suavizados no curto prazo, através do mercado de crédito. O grau de compartilhamento de risco de curto prazo com a inclusão do G6 e emergentes também é menor do que o valor intra América Latina e igual ao do América Latina mais G6. O parâmetro $\lambda$, também estimado pela equação (4) do modelo empírico, também com efeitos aleatórios, foi $\lambda=-0,11$. A interpretação do parâmetro é que o tempo para ajustamento do consumo dos países da América Latina é de aproximadamente -0,11. Para esse parâmetro, não há mudanças significativas em relação ao valor intra América Latina e entre América Latina mais G6.

\section{Resultados dos Estimadores de Compartilhamento de Risco e Testes Adicionais - Resultados do Teste de Hausman}

Segundo Greene (2003), o teste de Hausman é do tipo Wald. Ele tem como hipótese nula que as diferenças nos coeficientes não são sistemáticas, ou seja, os coeficientes do modelo e os efeitos aleatórios são ortogonais. Ao rejeitar a hipótese nula, o modelo de efeitos fixos é o melhor, dado que essa condição é essencial ao modelo de efeitos aleatórios. Para Wooldridge (2002), escolhemse efeitos aleatórios quando o efeito não observado é não correlacionado com as variáveis explicativas. Ao aplicar o teste de Hausman, não se rejeitou a hipótese nula de que os efeitos aleatórios ficam melhor para esse modelo (Tabela 4.3).

\section{Resultados dos Estimadores de Compartilhamento de Risco ao Longo do Tempo}

Os parâmetros de compartilhamento descritos no item anterior se referem ao período de estudo como um todo, de 1951 a 2003.

A seção atual tratará dos valores desses parâmetros em diferentes subperíodos para verificar suas mudanças no tempo, de acordo com os acontecimentos históricos da economia mundial, especialmente o período da segunda metade da década 1980 e primeira metade da década de 1990, marcado por uma maior globalização, que, segundo Artis \& Hoffmann (2006a) e Artis \& Hoffmann (2006b), promoveu maior compartilhamento de risco.

Para esse estudo, foram estimados os mesmos parâmetros $\beta, \gamma$ e $\lambda$ para cada dez anos. Esses parâmetros foram estimados de 1951 a 1960, de 1952 a 1961, até chegar a seus valores de 1994 a 2003. Tais resultados se encontram nas Figuras 1, 2 e 3, em que o ano final de cada subperíodo foi utilizado como referência. Assim, as figuras trazem como intervalo de tempo os anos de 1960 a 2003, exatamente o último ano de cada um dos 44 subperíodos para os quais os parâmetros $\beta, \gamma$ e $\lambda$ foram estimados.

Os parâmetros foram estimados apenas para a América Latina, para a América Latina considerando o G6 como fazendo parte dos agregados consumo e produção mundiais, e para a América Latina, considerando o G6 e os países emergentes como fazendo parte dos agregados consumo e produção mundiais. 
Tabela 3: Valores dos Parâmetros e Teste de Hausman - Comparação entre os Testes de Efeitos Aleatórios de Seção Cruzada label

\begin{tabular}{|c|c|c|c|c|}
\hline \multicolumn{5}{|c|}{ América Latina } \\
\hline \multicolumn{5}{|c|}{ H0: Efeitos Aleatórios é melhor } \\
\hline Parâmetros & Efeito Fixo & Efeito Aleatório & Var(Dif.) & P-Valor ${ }^{*}$ \\
\hline$\beta$ & 0,93 & 0,93 & 0,00 & 0,20 \\
\hline$\gamma$ & 0,80 & 0,80 & 0,00 & 0,71 \\
\hline$\lambda$ & $-0,11$ & $-0,11$ & 0,00 & 0,15 \\
\hline \multicolumn{5}{|c|}{ América Latina + G6 } \\
\hline \multicolumn{5}{|c|}{ H0: Efeitos Aleatórios é melhor } \\
\hline Parâmetros & Efeito Fixo & Efeito Aleatório & $\operatorname{Var}($ Dif.) & P-Valor $^{*}$ \\
\hline$\beta$ & 0,97 & 0,96 & 0,00 & 0,08 \\
\hline$\gamma$ & 0,85 & 0,85 & 0,00 & 0,86 \\
\hline$\lambda$ & $-0,11$ & $-0,11$ & 0,00 & 0,09 \\
\hline \multicolumn{5}{|c|}{ América Latina + G6 + Emergentes } \\
\hline \multicolumn{5}{|c|}{ H0: Efeitos Aleatórios é melhor } \\
\hline Parâmetros & Efeito Fixo & Efeito Aleatório & $\operatorname{Var}($ Dif.) & P-Valor $^{*}$ \\
\hline$\beta$ & 0,87 & 0,87 & 0,00 & 0,23 \\
\hline$\gamma$ & 0,85 & 0,85 & 0,00 & 0,89 \\
\hline$\lambda$ & $-0,11$ & $-0,11$ & 0,00 & 0,09 \\
\hline
\end{tabular}

* O valor de P é analisado ao nível de 5\% de significância estatística.

Fonte: Resultados da pesquisa.

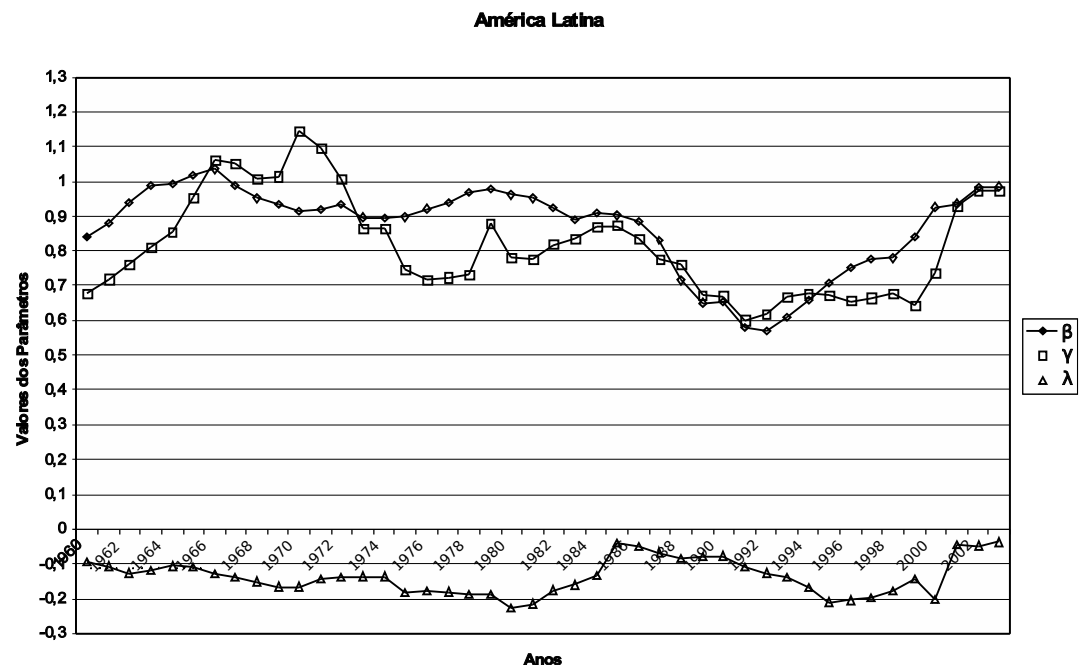

Fonte: Resultados da pesquisa.

Figura 1: Parâmetros ao longo do tempo para a América Latina 


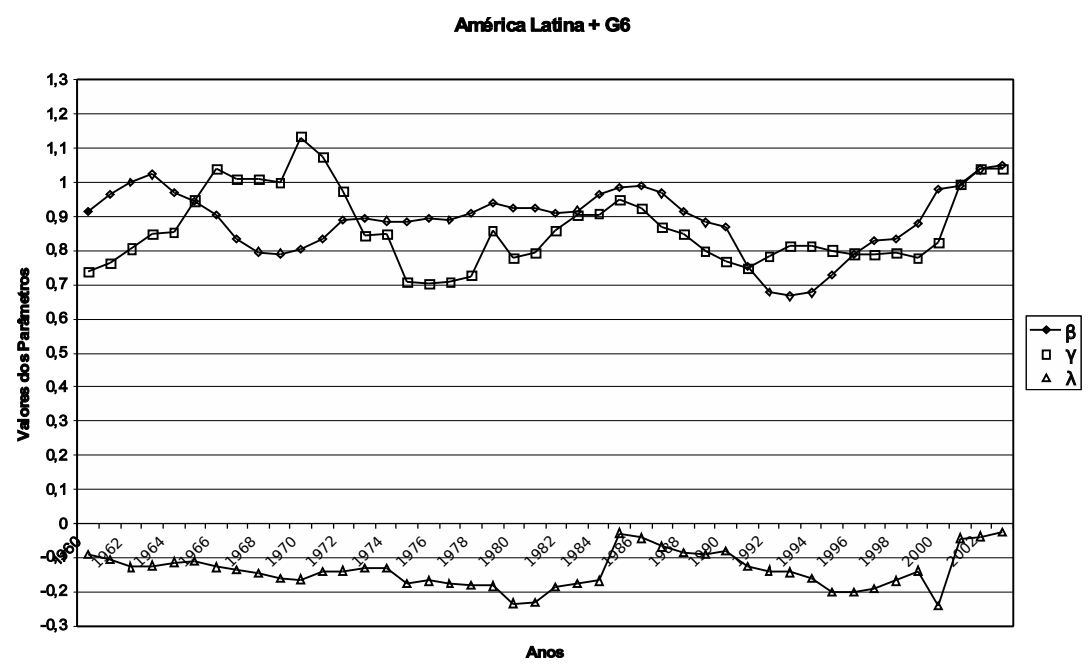

Fonte: Resultados da pesquisa.

Figura 2: Parâmetros ao longo do tempo para a América Latina + G6

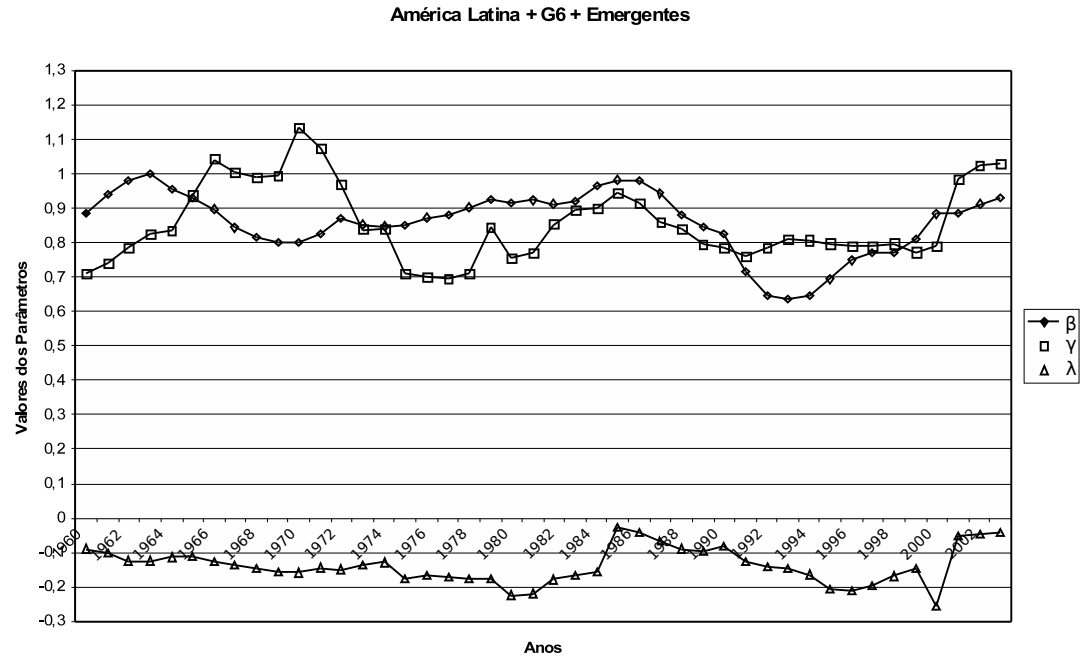

Fonte: Resultados da pesquisa.

Figura 3: Parâmetros ao longo do tempo para a América Latina + G6 + Emergentes 
Os parâmetros $\beta, \gamma$ e $\lambda$, ao longo do tempo, foram estimados para cada um dos 3 casos: América Latina; América Latina + G6; e América Latina + G6 + Emergentes. O significado de cada um dos parâmetros $\beta, \gamma$ e $\lambda$, é o mesmo já descrito na seção 3.1 .

Relacionando-se ao contexto histórico, observa-se que, na década de 1960, o compartilhamento de risco de curto prazo $(\gamma)$ na América Latina, para os três casos em estudo, reduze-se devido a instrumentos de créditos ainda pouco desenvolvidos e ao baixo acesso ao crédito internacional. Na primeira metade da década de 1970, aumenta vigorosamente, mantendo-se estável na segunda metade daquela década, resultado da flexibilização cambial. Na primeira metade da década de 1980, ele volta a reduzir-se, ficando muito baixo em meados da década, em decorrência da crise do endividamento dos países latinoamericanos. A partir daí, começa a aumentar, atingindo maior nível no início da década 1990, consequência do aprofundamento do processo da globalização. A partir da metade da década de 1990, reduz-se novamente, em decorrência do boom de consumo, segundo Kose et al. (2007), o que não permite sua suavização.

O compartilhamento de risco de longo prazo $(\beta)$ se reduz no início da década de 1960 e aumenta no final da década de 1960 e início da década de 1970, de forma mais acentuada nos grupos que incluem o G6 e G6 + Emergentes nos agregados mundiais. Esse aumento na década de 1970 estaria relacionado ao fim do Sistema Bretton Woods, com os regimes de câmbio passando a ser flutuantes. Já no final da década de 1970 e na primeira metade da década de 1980, uma nova queda estaria relacionada à crise do endividamento da América Latina. Ele aumenta de forma mais vertiginosa, na segunda metade da década de 1980 e primeira metade da década de 1990, período em que se promoveu maior abertura econômica. E volta a reduzir-se na segunda metade da década de 1990 e início dos anos 2000. Segundo Kose et al. (2007), o aumento do compartilhamento de risco na segunda metade da década de 1980 e primeira metade da década de 1990, na América Latina, não ter perdurado nos anos seguintes seria explicado pelo boom de consumo promovido pelo maior acesso a capitais internacionais e pela falta de um mecanismo de suavização de consumo mais eficiente, que seria uma mercado de capitais mais desenvolvido. Observa-se que a inclusão de outros países nos agregados mundiais, como o G6 e emergentes, faz o compartilhamento de risco começar a declinar apenas nos anos 2000 .

Por sua vez, o parâmetro $(\lambda)$ que mede o quanto um país mantém seu consumo estável, dados os choques no produto, mostra uma ampliação nesse tempo no decorrer nas décadas de 1960 e 1970, reduz-se em meados na década de 1980, passando a ampliar-se na segunda metade da década de 1980 até meados da década de 1990, quando volta a se reduzir sendo incluindo aí o período dos anos 2000.

\subsection{Análise Comparativa com outros trabalhos de Compartilhamento de Risco}

Esse tema, apesar de ter suas raízes nas primeiras relações comerciais, quando a economia mundial era bastante incipiente, é recente na literatura econômica, passando a ser estudado de forma muito mais enfática com o processo de globalização econômica mundial. Como um fenômeno recente, proporcio- 
nou aos países do mundo desenvolvido ganhos mais intensos e mais visíveis do que ao mundo subdesenvolvido.

Assim, é importante estudar o fenômeno do compartilhamento de risco para a América Latina, uma região composta por países predominantemente em desenvolvimento e/ou países emergentes. Para essa região, os trabalhos de maior relevância sobre o tema são ainda poucos, daí a importância de comparar tal trabalho com aqueles feitos para outras regiões.

Um importante trabalho sobre compartilhamento de risco foi feito por Leibrecht \& Scharler (2008), num estudo específico intra para a Europa. Ou seja, neste estudo, os autores buscaram inferir como os países europeus, representantes do bloco desenvolvido, estavam integrados entre si, deixando de lado a integração com o restante do mundo. Os resultados por eles encontrados para os mesmos parâmetros estimados no modelo empírico do presente trabalho foram $\beta=0,89, \gamma=0,71$ e $\lambda=-0,10$. Tais resultados mostraram um compartilhamento de risco maior do que o da América Latina, onde os parâmetros do presente trabalho foram: $\beta=0,93, \gamma=0,80$ e $\lambda=-0,11$, sem a inclusão de G6 e emergentes nos agregados mundiais. É importante ressaltar que o trabalho de Leibrecht e Scharler (2008) não estimou parâmetros de compartilhamento de risco para o bloco dos países europeus em relação ao resto mundo.

Para Ventura (2008), que estudou o compartilhamento de risco de países da América Latina e do Caribe no período de 1972-2003, os parâmetros estimados mostraram que os países da região sofrem, claramente, maior influência de choques idiossincráticos, afetando seu consumo e sua produção.

$\mathrm{Na}$ análise interpaíses, o presente trabalhou mostra que, incluindo países emergentes, o parâmetro de compartilhamento de risco é maior, pelo menos no longo prazo. Segundo Ventura (2008), a América Latina seria mais vulnerável a choques idiossincráticos do que a choques mundiais, e a sua integração a outros mercados, como os emergentes, reduziria sua exposição a choques específicos em sua economia.

Portanto, os resultados obtidos no presente trabalho são corroborados por outros importantes trabalhos da literatura econômica.

\section{Conclusão}

Este trabalho estudou o compartilhamento de risco entre os países da América Latina, intra-América Latina e inter-América Latina e outros mercados, além de estudar o comportamento do compartilhamento de risco na América Latina no período.

O presente trabalho buscou também verificar como os diversos acontecimentos econômicos influenciaram o grau de integração entre os países latinoamericanos, nos vários períodos de tempo. O principal deles foi o processo de intensificação da globalização da década de 1990.

Devido aos trabalhos sobre esse tema, especificamente para essa região, serem recentes e aqueles de grande relevância ainda em número não muito significativo, os resultados foram comparados com um estudo sobre o mesmo tema, mas para a região da Europa, no caso intra. No caso interpaíses, a comparação teve por base o trabalho que utilizou países da América Latina e Caribe.

Constatou-se, como era de se esperar, que o grau de compartilhamento de risco intrapaíses da América Latina é baixo, sendo inferior ao nível encontrado 
nos países desenvolvidos, como os países europeus, na análise intra-América Latina. Isto significa dizer que os países latino-americanos, desconsiderando o resto do mundo, são menos integrados do que o bloco europeu, também desconsiderando o resto do mundo. Mesmo assim, para o parâmetro de curto prazo, o compartilhamento de risco na América Latina mostrou ser maior do que nos dois casos interpaíses.

Em termos interpaíses, constatou-se que o compartilhamento de risco é menor entre América Latina e países desenvolvidos (G6), do que intra-América Latina. Isso poderia ser explicado pelo fato de os países latino-americanos tenderem a realizar maiores transações comerciais e financeiras com seus vizinhos, exatamente por possuírem características mais comuns, como maior proximidade geográfica, menores custos de transação, níveis de desenvolvimento educacional, político e cultural próximos etc. Assim, o mesmo com o nível de compartilhamento de risco sendo em geral baixo, apenas intraAmérica Latina, ele tende a ser relativamente maior.

Esse grau de compartilhamento de risco aumenta quando países emergentes são incluídos. Aqui surgiria uma importante oportunidade para os países latino-americanos e outros com características semelhantes. Como a economia de muitos países dessa região é pequena, a oportunidade de aumento de compartilhamento de risco intra poderia não ser muito grande. Mas, como em outras regiões do globo, há muitas economias emergentes, já consideradas grandes ou em crescimento, os países da América Latina poderiam obter ganhos transacionando ativos com esses países, de características semelhantes. Isso foi observado para o parâmetro de longo prazo.

O que explicaria a diferença nos resultados intra-América Latina com relação à Europa, por exemplo, seria a integração financeira dos países. A Europa possui maior abertura comercial, mercados financeiros mais desenvolvidos e mais integrados. Já a diferença interpaíses, que a América Latina compartilha menos risco com o G6 do que com os emergentes, poderia ser explicada pelas próprias barreiras comerciais e financeiras que os países desenvolvidos impõem aos países em desenvolvimento.

Com relação ao compartilhamento de risco na América Latina ao longo do período em estudo, observou-se que, em períodos de maior crescimento econômico ou de maior expansão da economia, o compartilhamento de risco tende a ser maior, principalmente em decorrência das oportunidades surgidas em função de uma maior integração dos mercados. No período de maior intensificação da globalização econômica e financeira, no final dos anos de 1980 e início dos anos de 1990 em diante, observa-se que os ganhos para os países da América Latina, assim como para a maioria dos países e desenvolvimento e emergentes, não mostraram ser tão significativos. A maior abertura econômica demonstrou ter mais impactos sobre o compartilhamento de risco dos países desenvolvidos.

Comparando os resultados para a América Latina com os de regiões mais desenvolvidas, como o bloco europeu, ou até mesmo o bloco asiático, observase que a América Latina não se aproveitou tão bem do processo de globalização como outros países o fizeram.

Os resultados mostraram também que a abertura econômica, por si só, não garante mais ganhos em termos de estabilidade do consumo em relação a choques idiossincráticos, nem maiores ganhos relacionados ao crescimento econômico e ao bem-estar de um país. Tais ganhos poderiam estar relacionados a outros fatores, como reformas estruturais no país, medidas de austeri- 
dade fiscal e monetária e investimentos em educação e tecnologia. No início da década de 1990, a maioria dos países da América Latina passou a promover algumas reformas denominadas pró-mercado, como parte do chamado Consenso de Washington. Essas reformas englobavam maior liberalização econômica, privatizações e uma desregulamentação da economia, ou seja, uma menor atuação do governo na atividade econômica, deixando a economia seguir o que era ditado pelo próprio mercado.

Mesmo com essas reformas, os ganhos dos países em desenvolvimento demonstraram ser menores do que os ganhos dos países desenvolvidos, com o processo de globalização. Uma explicação poderia estar no fato de essas reformas terem sido mais profundas no mundo desenvolvido e menos profundas nos países em desenvolvimento.

Tais resultados levam a concluir que os países da América Latina poderiam melhorar sua situação econômica pela ampliação do compartilhamento de risco, mas um maior nível de integração não foi ainda alcançado devido à ausência de reformas econômicas e institucionais que fizessem com que os países latino-americanos aproveitassem de melhor maneira as vantagens proporcionadas pela globalização.

Em termos de compartilhamento de risco intra-América Latina, haveria a necessidade de um maior desenvolvimento e de uma maior integração de seus mercados. Em termos interpaíses, a América Latina deveria adentrar os mercados dos países desenvolvidos, ainda restritos, quebrando as barreiras existentes, ou ampliar sua integração com os países emergentes. Pelos resultados encontrados no presente trabalho, os latino-americanos tendem a ter uma maior integração com países com características econômicas mais próximas, como alguns emergentes, e tais oportunidades podem e devem ser aproveitadas.

\section{Referências Bibliográficas}

Allen, F. \& Gale, D. (1994), Financial Innovation and Risk Sharing, MIT Press.

Arrow, K. J. (1964), 'The role of securities in the optimal allocation of risk bearing.', Review of Economic Studies 31, 91-96.

Arrow, K. J. (1996), 'Theory of risk-bearing: Small and great risks', Journal of Risk and Uncertainty 12, 103-111.

Artis, M. J. \& Hoffmann, M. (2006a), Declining home bias and the increase in international risk sharing: Lessons from european integration., Technical report, University of Manchester.

Artis, M. J. \& Hoffmann, M. (2006b), The home bias and capital income flows between countries and regions, Technical report, Centre for Economis Policy Research.

Canova, F. \& Ravn, M. (1996), 'International consumption risk sharing', International Economic Review 37, 573-601.

Crucini, M. \& Hess, G. D. (2000), International and intranational risk sharing., in 'Intranational Macroeconomics', Cambridge University Press. 
Debreu, G. (1959), Theory of Value, Yale University Press.

Greene, W. H. (2003), Econometric Analysis, Prentice-hall.

Heston, A., Summers, R. \& Aten, B. (2006), Penn world table version 6.2, Technical report, Center for International Comparisons of Production, Income and Prices at the University of Pennsylvania, http://pwt.econ.upenn.edu/.

Kaminsky, G. L. \& Schmukler, S. L. (2003), Short run pain, long run gain: The effects of financial liberalization., Technical report, National Bureau of Economic Research.

Kose, M. A., Prasad, E. S., Rogoff, K. \& Wei, S. J. (2006), Financial globalization: A reappraisal., Technical report, International Monetary Fund.

Kose, M. A., Prasad, E. S. \& Terrones, M. E. (2007), How does financial globalization affect risk-sharing? patterns and channels., Technical report, International Monetary Fund.

Leibrecht, M. \& Scharler, J. (2008), Reconsidering consumption risk sharing among oecd countries: Some evidence based on panel integration, Technical report, Open Economies Review.

Lewis, K. K. (1996), 'What can explain the apparent lack of international consumption risk sharing.', Journal of Political Economy 104, 267-297.

Lewis, K. K. (1999), 'Trying to explain home bias in equities and consumptions.', Journal of Economic Literature 37, 571-608.

Obstfeld, M. (1994), Are industrial-country consumption risks globally diversified?, in 'Capital Mobility: The Impact of Consumption, Investment and Growth', Cambridge University Press.

Obstfeld, M. \& Rogoff, K. (1996), Foundations of International Macroeconomics., MIT Press.

Schmukler, S. L. (2004), 'Financial globalization: gain and pain for developing countries', Economic Review. Q2, 39-66.

Sorensen, B. E. \& Yosha, O. (1998), 'International risk sharing and european monetary unification.', Journal of International Economics 45, 211-238.

Torre, A. \& Schmukler, S. L. (2007), Emerging Capital Markets and Globalization: The Latin America Experience, Stanford University Press and World Bank.

Ventura, L. (2008), Risk sharing opportunities and macroeconomic factors in latin american and caribbean countries: A consumption insurance assessment., Technical report, The World Bank, Latin America and the Caribbean Region.

Wooldridge, J. M. (2002), Econometric Analysis of Cross Section and Panel Data, The MIT Press. 


\section{Apêndice A Modelo Teórico}

\section{A.1 Negócios entre estados da natureza: Choques Específicos do País}

Como forma de simplificação, parte-se de um país, onde existem apenas dois períodos de tempo e dois estados da natureza. O país possui uma economia aberta, podendo negociar títulos nos mercados mundiais, mas a produção do país e suas decisões de maximização sofrem influência apenas de choques específicos do país.

\section{Utilidade Esperada Intertemporal - Incerteza e Preferências}

Um indivíduo com renda futura incerta não pode prever com exatidão seu nível de consumo futuro. Dessa forma, ele tenta prever sua renda futura de acordo com os possíveis estados da natureza que possam ocorrer, influenciando o nível de produção. Cada um dos estados da natureza tem uma probabilidade de ocorrência.

Como forma de simplificação do modelo, parte-se da pressuposição de que a vida do indivíduo em estudo é dividida em dois períodos, 1 e 2 . Ao final do período 2, toda a renda do indivíduo deve ser consumida.

Assim, a utilidade esperada da vida do indivíduo seria dada pela equação:

$$
U_{1}=\pi(1)\left\{u\left(C_{1}\right)+\beta u\left[C_{2}(1)\right]\right\}+\pi(2)\left\{u\left(C_{1}\right)+\beta u\left[C_{2}(2)\right]\right\}
$$

Como $\pi(1)+\pi(2)=1$, resulta que

$$
U_{1}=u\left(C_{1}\right)+\pi(1) \beta u\left[C_{2}(2)\right]+\pi(2) \beta u\left[C_{2}(2)\right]
$$

em que:

$U_{1}=$ Utilidade Esperada Intertemporal do Indivíduo, no Tempo 1;

$\pi(s)=$ Probabilidade de que o estado da natureza s ocorra. $(s=1,2)$;

$u\left(C_{1}\right)=$ Utilidade do consumo do período 1 ;

$u\left(C_{2}(s)\right)=$ Utilidade do consumo do período 2 se o estado da natureza $s$ ocorrer, $(s=1,2)$;

$u\left(C_{2}(2)\right)=$ Utilidade do consumo do período 2 se o estado da natureza 2 ocorrer; e

$\beta=$ fator de desconto $(1 /(1+r))$ para o consumo do indivíduo no período 2 .

\section{Mercado Completo de Ativos e Seguros Arrow-Debreu}

$\mathrm{O}$ possuidor do seguro recebe uma unidade de produto na data 2 se o estado da natureza $s$ ocorrer, mas não recebe nada, caso contrário. Isso é o chamado seguro Arrow-Debreu. Assume-se que há um mercado competitivo para seguros Arrow-Debreu para cada estado da natureza s (OBSTFELD e ROGOFF, 1996).

Obviamente, continuam existindo os ativos ou títulos não contingenciados, que são aqueles que pagam $(1+r)$ por unidade na data 2 , independentemente de que estado na natureza ocorra. ( $r$ representa a taxa de juros sem risco do mercado. Um exemplo seria a taxa básica de juros, a Selic). 
Se existem seguros Arrow-Debreu para cada estado, entretanto, o mercado de títulos é redundante, dado que sua eliminação não afetaria o equilíbrio da economia.

Com apenas dois estados da natureza, a compra simultânea de $(1+r)$ estado 1 do seguro Arrow-Debreu e $(1+r)$ estado 2 do seguro Arrow-Debreu assegura o pagamento de $(1+r)$ unidades de produto no período 2 , independentemente do estado da economia, como faz um título (OBSTFELD e ROGOFF, 1996).

Pode-se dizer que títulos não oferecem nada além das oportunidades que as pessoas têm quando um conjunto completo de ativos do tipo Arrow-Debreu pode ser negociado.

Os ativos do tipo Arrow-Debreu, que se relacionam com estados da natureza, englobam todos os títulos que pagam apenas um prêmio sem risco, sendo um conjunto mais amplo, pois pagam também um prêmio de risco, relacionado aos estados da natureza.

Além disso, todos os ativos mais complexos, como as opções, derivam dos ativos do tipo Arrow-Debreu.

Quando se diz que uma economia tem um mercado completo de ativos, significa que as pessoas podem negociar um seguro Arrow-Debreu correspondendo a todo estado futuro da natureza.

\section{A.2 Restrição Orçamentária com Seguros Arrow-Debreu}

Faz-se a análise da restrição orçamentária de um país sob incerteza e mercados completos de ativos.

$B_{2}(s)$ refere-se à aquisição líquida do estado da natureza s para seguros Arrow-Debreu na data 1. É, portanto, o estoque de seguros Arrow-Debreu que o indivíduo possui no final da data 1 e início da data 2.

Seja $p(s) /(1+r)$ o preço mundial, cotado em termos do consumo presente, ou seja, na data 1 , um desses seguros - que é o direito de receber uma unidade de produto na data 2 , se e somente se o estado da natureza socorrer.

Numa economia de trocas, o total de ativos que um indivíduo acumula na data 1, deve ser igual à diferença entre o que ele recebe, em termos de renda e o que ele consome. Essa relação pode ser dada pela seguinte equação:

$$
\frac{p(1)}{1+r} B_{2}(1)+\frac{p(2)}{1+r} B_{2}(2)=Y_{1}-C_{1}
$$

em que:

$B_{2}=$ Aquisição líquida de ativos;

$Y_{1}=$ Renda do período $1 ; \mathrm{e}$

$C_{1}=$ Consumo do período 2 .

Não há a necessidade de considerar títulos, pois eles estão incluídos nos seguros Arrow-Debreu.

Quando se chega à data 2, o estado da natureza s é observado, e o país estará apto a consumir sua renda mais possíveis ganhos provenientes dos seus ativos relacionados ao estado da natureza s. Assim, tem-se:

$$
C_{2}=Y_{2}(s)+B_{2}(s), \quad s=1,2
$$

Equivalentemente, o consumo presente mais o valor presente do consumo futuro deve ser igual à renda presente mais o valor presente da renda futura. 
Partindo das equações (5), (6) e (7), e após algumas manipulações algébricas, tem-se:

$$
C_{1}+\frac{p(1) C_{2}(1)+p(2) C_{2}(2)}{1+r}=Y_{1}+\frac{p(1) Y_{2}(1)+p(2) Y_{2}(2)}{1+r}
$$

Assim, com a existência dos mercados internacionais, os países podem suavizar seu consumo não apenas ao longo do tempo, mas para cada diferente estado da natureza. Nesse último caso, a suavização do consumo ocorre somente se o preço atuarial for justo.

Se a oferta para o estado da natureza 1 for baixa e para o estado da natureza 2 for alta, pode-se fazer o seguinte: reduzir $B_{2}(2)$ (aquisição líquida de ativos, caso o estado da natureza 1 ocorra) e ampliar $B_{2}(1)$ (aquisição líquida de ativos, caso o estado da natureza 2 ocorra), suavizando o consumo entre os estados da natureza.

Para que um país obtenha níveis de poupança e de carteira de ativos considerados ótimos, ele deve maximizar sua utilidade esperada, que é dada pela equação (5), e sujeita a uma restrição, dada pela equação (6).

Finalmente, utilizam-se as equações (6) e (7) para expressar níveis de consumo na equação (5), como função da escolha dos ativos. Como resultado, deve-se maximizar a equação contendo a carteira de títulos acumulados ao final do período 1 (que coincide com o início do período 2), de acordo com cada estado da natureza. ( $B_{2}(1)$ se o estado 1 ocorrer ou $B_{2}(1)$ se o estado 2 ocorrer). Essa equação, sem uma restrição, é dada por:

$$
U_{1}=u\left[Y_{1}-\frac{p(1)}{1+r} B_{2}(1)-\frac{p(2)}{1+r} B_{2}(2)\right]+\sum_{s=1}^{2} \pi(s) \beta u\left[Y_{2}(s)+B_{2}(s)\right]
$$

Dessa equação, retiram-se as condições de primeira ordem, resultando em:

$$
\frac{p(s)}{1+r} u^{\prime}\left(C_{1}\right)=\pi(s) \beta u^{\prime}\left[C_{2}(s)\right], \quad s=1,2 .
$$

A equação (9) resultante é a chamada equação intertemporal de Euler. Embora a equação de Euler seja especificada inicialmente para títulos livres de risco, ela é válida também para o presente estudo relacionado a títulos que possuam algum nível de risco, os seguros Arrow-Debreu. O lado direito da equação é o benefício esperado na na data 2 , descontado pela taxa de juros, de se ter uma unidade adicional para consumir da data 2. Já o lado esquerdo da equação de Euler é o custo, em termos de utilidade marginal da data 1, de adquirir seguros Arrow-Debreu para o estados.

\section{A.3 Um Modelo Global}

\section{O Caso da Aversão ao Risco Relativo Constante}

No modelo global, a economia de um país é influenciada por choques específicos de sua economia e por choques na economia mundial. A economia mundial é composta por duas economias, a interna e o resto do mundo, com os níveis de oferta variando de acordo com os diferentes estados da natureza $s$, indo esses estados até $S>2$. A2. A condição de equilíbrio geral global requer as seguintes equações: 


$$
\begin{gathered}
C_{1}+C_{1}^{*}=Y_{1}+Y_{1}^{*} \\
C_{2}(s)+C_{2}^{*}(s)=Y_{2}(s)+Y_{2}^{*}(s) s=1,2, \ldots,
\end{gathered}
$$

Observa-se pela equação (11) que, no período 1, a soma do consumo interno e do resto do mundo se iguala à soma das produções interna e do resto do mundo. No período 2, essa igualdade também deve ocorrer, mas nele há um fator estocástico, pois podem ocorrer diferentes estados da natureza.

Os preços de equilíbrio são alcançados combinando-se as condições de mercado aberto com aquelas observadas na equação de Euler, da seção anterior. Assim, chega-se à equação:

$$
\frac{p(s)}{1+r}=\pi(s) \beta\left[\frac{Y_{2}^{w}(s)}{Y_{1}^{w}}\right]^{-\rho}, \quad s=1,2, \ldots, S .
$$

Observação: Quanto maior o $\rho$, menor a elasticidade de substituição intertemporal.

Em um modelo que considere mercados completos, é dada uma grande ênfase às correlações nos níveis de consumo internacionais, na alocação intertemporal ou na alocação entre os diferentes estados da natureza. Isso ocorre porque a existência de mercados completos permite que todos os indivíduos, de um país local ou do restante do mundo, equalizem suas taxas marginais de substituição dos consumos presente e futuro.Essa equalização é representada pela próxima equação, obtida pelo incremento à equação (1.5A), com vários estados da natureza. Tem-se:

$$
\frac{\pi(s) \beta u^{\prime}\left[C_{2}(s)\right]}{u^{\prime}\left(C_{1}\right)}=\frac{p(s)}{(1+r)}=\frac{\pi(s) \beta u^{\prime}\left[C_{2}^{*}(s)\right]}{u^{\prime}\left(C_{1}^{*}\right)}
$$

A equação (13) implica que:

$$
\frac{\pi(s) u^{\prime}\left[C_{2}(s)\right]}{\pi\left(s^{\prime}\right) u^{\prime}\left[C_{2}\left(s^{\prime}\right)\right]}=\frac{p(s)}{p\left(s^{\prime}\right)}=\frac{\pi(s) u^{\prime}\left[C_{2}^{*}(s)\right]}{u^{\prime}\left(C_{1}^{*}\right)},
$$

sendo essa a condição necessária para a alocação eficiente dos recursos. Caso as taxas marginais de substituição de todos os indivíduos se igualem, tanto ao longo do tempo como entre estados da natureza, a possibilidade de ganhos com negociação de ativos se esgotará.

Com uma função de utilidade com aversão ao risco relativo constante, e partindo-se da equação $(2.3 \mathrm{~A})$, com, por exemplo, $\mathrm{u}^{\prime}(\mathrm{C})=\mathrm{C}-\rho$, chega-se às seguintes equações:

$$
\begin{aligned}
& \frac{C_{2}(s)}{C_{2}\left(s^{\prime}\right)}=\frac{C_{2}^{*}(s)}{C_{2}^{*}\left(s^{\prime}\right)}=\frac{Y_{2}^{w}(s)}{Y_{2}^{w}\left(s^{\prime}\right)} \\
& \frac{C_{2}(s)}{C_{1}}=\frac{C_{2}^{*}(s)}{C_{1}^{*}}=\frac{Y_{2}^{w}(s)}{Y_{1}^{w}}
\end{aligned}
$$

que mostram ser o consumo doméstico uma fração constante $\mu$ da produção mundial da data 2, independentemente de qual estado da natureza ocorra. Isso seria válido se todos os países tivessem uma aversão ao risco constante e igual $\rho$, para todos eles. 
Ampliando o modelo, ainda que com dois países $n$ e $m$ com aversões ao risco constantes, mas diferentes para cada um deles, sendo dadas por $\rho_{n}$ e $\rho_{m}$, e com diferentes fatores de desconto $\beta_{n}$ e $\beta_{m}$, obter-se-iam boas previsões empíricas. Para $c$ igual ao consumo per capita e $y$ igual à renda per capita, a equação resultante seria:

$$
\log \left[\frac{c_{2}^{n}(s)}{c_{1}^{n}}\right]=\left(\frac{\rho_{m}}{\rho_{n}}\right) \log \left[\frac{c_{2}^{m}(s)}{c_{1}^{m}}\right]+\frac{1}{\rho_{n}} \log \left(\frac{\beta_{n}}{\beta_{m}}\right)
$$

A tradução dessa equação é que a taxa de crescimento do consumo dos países, embora individualmente aleatória, é perfeitamente correlacionada estatisticamente. 